Федотова Наталья Дмитриевна

младший научный сотрудник

Института гуманитарных исследований и проблем малочисленных народов Севера

Сибирского отделения Российской академии наук

\section{К ПРОБЛЕМЕ РАЗВИТИЯ ДОШКОЛЬНЫХ УЧРЕЖДЕНИЙ И СОЦИАЛИЗАЦИИ ДЕТЕЙ В РЕСПУБЛИКЕ САХА (ЯКУТИЯ)}

Аннотация:

В статье рассматриваются детские дошкольные учреждения в Республике Саха (Якутия), которые играют одну из важнейших ролей в процессе социализации детей. На основе статистической информации из официальных источников автором проведен анализ некоторых изменений в сфере дошкольного образования в регионе по определенным показателям, характеризующим доступность и охват детей данным образованием. На фоне сокращения числа учреждений изучаемого сегмента на протяжении ряда лет в Республике Саха развивается вариативность форм организаций. Выявлены положительные и отрицательные стороны подобной трансформации в области дошкольного образования на современном этапе. На основе оценки результатов конкретного автором социологического исследования выявлена степень удовлетворенности опрошенных доступностью и качеством дошкольных образовательных услуг.

Ключевые слова:

дошкольные образовательные учреждения, доступность дошкольного образования, охват детей, социализация, Республика Саха (Якутия).
Fedotova Natalia Dmitrievna

Junior Research Fellow, Institute for Humanities Research and Indigenous Studies of the North, Siberian Branch of the Russian Academy of Sciences

\section{CONCERNING THE DEVELOPMENT OF PRESCHOOL INSTITUTIONS AND THE SOCIALIZATION OF CHILDREN IN THE REPUBLIC OF SAKHA (YAKUTIA)}

Summary

The study discusses preschool institutions in the Republic of Sakha (Yakutia) which play a major role in the socialization of children. Based on official statistics, the author conducts a detailed analysis of changes in several indicators of preschool education, its availability, and the number of children involved in it in the region. While the number of preschool educational institutions has decreased, there have been many new forms of such organizations in the Republic of Sakha (Yakutia) in recent years. The study reveals the positive and negative aspects of such transformation in the field of preschool education at the present stage. The sociological survey results help identify the level of respondents' satisfaction with the availability and quality of preschool educational services.

Детские дошкольные учреждения выступают значимыми агентами социализации. Они входят в систему образования и, будучи социальными организациями, созданы для реализации определенных целей, а именно образования, воспитания, физической и психологической подготовки к школьной жизни, привития и воспитания духовно-нравственных ориентиров, становления гармоничной личности [1, с. 14]. Образование является важнейшим ресурсом развития основных сорер жизнедеятельности общества, необходимым условием успешной социализации и самореализации личности [2, с. 264].

Теоретико-методологическую базу исследования составляют классические социологические труды, работы современных социологов, педагогов, психологов, демографов, посвященные вопросам социализации и дошкольного образования (Э. Дюркгейма, Т. Парсонса, П.А. Сорокина, И.С. Кона, Ж. Пиаже, А.В. Мудрика, Д.И. Фельдштейна, В.Я. Нечаева, В.С. Собкина, Е.А. Виноградовой, О.В. Антоновой, Н.А. Вальнер и др.). Работа предполагает опору на структурный функционализм, символический интеракционизм. Необходимо также отметить, что особого внимания при изучении проблем детства требуют труды авторов, развивающих другие теоретические подходы (С.Н. Майоровой-Щегловой, А.А. Бесчасной, Е.А. Колосовой, О.А. Гуркиной, Д. Бюлер-Нидербергер, X. Зюнкера и др.). Кроме того, для оценки проблемного поля важное значение имеют публикации региональных специалистов (Т.С. Мостаховой, С.А. Сукнёвой, В.Б. Игнатьевой, У.А. Винокуровой и др.) [3].

Якутия традиционно характеризуется высокой рождаемостью, соответственно, потребность в услугах детских учреждений высока. Рассмотрение особенностей народонаселения показывает, что численность детей в возрасте 0-6 лет в общем составе на 1 января 2018 г. равнялась 111421 чел., или 11,6 \%. Для сравнения, их число в 2010 г. составляло 103977 чел., или 10,8 \%. В сельской местности группа детей данного возраста достигала 13,1 \%, в городской - 10,7 \% [4]. 
По показателю естественного прироста республика характеризуется положительной тенденцией, в абсолютном большинстве улусов (районов) в 2017 г. наблюдался прирост, при этом в большей их части (15 и город Якутск) он был выше среднерегионального значения (6,4 на 1 тыс. чел.): в Анабарском - 14,7; Оленекском - 12,7; Верхневилюйском - 10,8; Таттинском - 10,4; Чурапчинском - 9,7; Намском - 9,6; Мегино-Кангаласском - 8,9; Вилюйском - 8,9; Якутске - 8,7; Амгинском - 8,6; Нюрбинском - 8,2; Усть-Алданском - 8,1; Сунтарском - 8,0; ЭвеноБытантайском - 7,2; Момском - 7,1; Кобяйском - 6,4. В 13 улусах естественный прирост был ниже среднереспубликанского значения: Абыйском - 0,7; Аллаиховском - 2,2; Булунском - 6,3; Верхоянском - 5,3; Ленском - 0,8; Мирнинском - 5,2; Нерюнгринском - 1,4; Нижнеколымском - 1,3; Олекминском - 1,6; Томпонском - 1,7; Среднеколымском - 5,8; Усть-Янском - 2,6; Хангаласском - 4,7. Естественная убыль отмечалась только в четырех улусах: Верхнеколымском (-2,9 на 1 тыс. чел.), Оймяконском (-2,2), Алданском и Усть-Майском (по -1,9) [5, с. 44]. Как видно, естественный прирост выше среднерегиональной величины характерен для улусов с преобладанием сельских жителей, прирост ниже зарегистрированного в целом по региону и естественная убыль - в основном для промышленных улусов с городскими жителями.

Якутия отличается рядом особенностей, которые определяют уровень доступности социальных услуг, а именно - дисперсным характером расселения граждан, низкой плотностью населения, транспортной труднодоступностью и изолированностью поселений, неравномерностью уровня жизни городских и сельских жителей.

Одной из главных проблем в сфере дошкольного образования является дефицит мест в детских организациях. В качестве основных показателей оценки сети дошкольных образовательных учреждений (ДОУ) выступают количество детских садов и детей в них. Выделим показатель доступности. Согласно статистическим данным за период с 2000 по 2010 г., как видно из таблицы 1, в целом по республике сокращалось число детских садов, при этом в городской местности уменьшение составило 24 ед., в сельской - 21. Однако в 2010 г. открылись группы, организованные в школах, их насчитывалось 30 ед.

Таблица 1 - Число ДОУ (с учетом организаций на капитальном ремонте) на конец года, ед. [6, с. 249]

\begin{tabular}{|l|c|c|c|}
\hline \multicolumn{2}{|c|}{ Местность } & \multicolumn{3}{|c|}{ Год } \\
\cline { 2 - 4 } & $\mathbf{2 0 0 0}$ & $\mathbf{2 0 0 5}$ & $\mathbf{2 0 1 0}$ \\
\hline Города и поселки городского типа & 250 & 237 & 226 \\
\hline Сельская местность & 510 & 514 & 489 \\
\hline Всего по Якутии & 760 & 751 & 715 \\
\hline
\end{tabular}

C 2014 г. фриксируется расширение фрорм дошкольных учреждений, как следует из таблицы 2. При сокращении в период с 2014 по 2017 г. числа организаций, осуществляющих образовательную деятельность по программам дошкольного образования, присмотр и уход за детьми, наблюдалось увеличение количества групп, сформированных при образовательных организациях различного уровня, а также филиалов образовательных организаций, осуществляющих образовательную деятельность по образовательным программам дошкольного образования, присмотр и уход за детьми.

Таблица 2 - Число организаций, осуществляющих образовательную деятельность по образовательным программам дошкольного образования, присмотр и уход за детьми, на конец года ${ }^{*}$, ед. [7, с. 250]

\begin{tabular}{|c|c|c|c|c|}
\hline \multirow{2}{*}{ Учреждение } & \multicolumn{4}{|c|}{ Год } \\
\hline & 2014 & 2015 & 2016 & 2017 \\
\hline $\begin{array}{l}\text { Организации, осуществляющие образовательную } \\
\text { деятельность по образовательным программам дошкольного } \\
\text { образования, присмотр и уход за детьми, в том числе: }\end{array}$ & 730 & 732 & 727 & 720 \\
\hline $\begin{array}{l}\text { самостоятельные дошкольные образовательные } \\
\text { организации }\end{array}$ & 653 & 641 & 614 & 605 \\
\hline $\begin{array}{l}\text { группы, открытые при общеобразовательных } \\
\text { организациях }\end{array}$ & 75 & 88 & 108 & 110 \\
\hline $\begin{array}{l}\text { группы, сформированные при профессиональных } \\
\text { образовательных организациях и образовательных } \\
\text { организациях высшего образования }\end{array}$ & - & - & 2 & 2 \\
\hline $\begin{array}{l}\text { группы, организованные при организациях } \\
\text { дополнительного образования }\end{array}$ & 2 & 3 & 3 & 3 \\
\hline $\begin{array}{l}\text { Филиалы образовательных организаций, осуществляющих } \\
\text { образовательную деятельность по образовательным } \\
\text { программам дошкольного образования, присмотр и уход за детьми }\end{array}$ & 28 & 32 & 32 & 34 \\
\hline
\end{tabular}
остановлена.

С учетом организаций на капитальном ремонте и организаций, деятельность которых при- 
По данным Территориального органа ФСГС по РС (Я), наблюдается повышение мощности доУ как в целом по региону, так и в сельской местности. Наибольшее количество мест было введено в целом по республике в 2015 г., как видно из таблицы 3. Необходимо отметить, что в разные годы увеличение числа мест в детских садах было сконцентрировано в сельской местности.

Таблица 3 - Ввод в действие мощности дошкольных образовательных учреждений [8, с. 272]

\begin{tabular}{|l|c|c|c|c|c|c|c|}
\hline \multicolumn{1}{|c|}{ Показатель } & $\mathbf{2 0 0 0}$ & $\mathbf{2 0 0 5}$ & $\mathbf{2 0 1 0}$ & $\mathbf{2 0 1 4}$ & $\mathbf{2 0 1 5}$ & $\mathbf{2 0 1 6}$ & $\mathbf{2 0 1 7}$ \\
\hline Мест в ДОУ & 455 & 372 & 440 & 1225 & 2378 & 555 & 2163 \\
\hline $\begin{array}{l}\text { В том числе в } \\
\text { сельской местности }\end{array}$ & 175 & 372 & 330 & 995 & 888 & 555 & 1698 \\
\hline
\end{tabular}

Согласно официальным источникам, дополнительные места создаются благодаря строительству, реконструкции, выкупу зданий и развитию вариативных форм (семейных групп, групп кратковременного пребывания и др.) [9]. Это в свою очередь позволило расширить доступность дошкольного образования.

Согласно статистической информации возможности дошкольных учреждений по охвату детей образованием в 2000 г. были чуть выше в городских поселениях. С 2014 по 2017 г., как видно из таблицы 4, ситуация изменялась в сторону сельских дошкольных учреждений. Здесь охват детей имеет положительную динамику.

Таблица 4 - Охват детей дошкольным образованием на конец года, \% [10, с. 249-250]

\begin{tabular}{|l|c|c|c|c|c|c|c|}
\hline \multirow{2}{*}{\multicolumn{1}{|c|}{ Местность }} & \multicolumn{7}{c|}{ Год } \\
\cline { 2 - 8 } & $\mathbf{2 0 0 0}$ & $\mathbf{2 0 0 5}$ & $\mathbf{2 0 1 0}$ & $\mathbf{2 0 1 4}$ & $\mathbf{2 0 1 5}$ & $\mathbf{2 0 1 6}$ & $\mathbf{2 0 1 7}$ \\
\hline $\begin{array}{l}\text { Города и поселки } \\
\text { городского типа }\end{array}$ & 64,5 & 65,1 & 63,2 & 63,5 & 67,9 & 67,7 & 67,8 \\
\hline Сельская местность & 63,5 & 68,7 & 57,1 & 68,1 & 70,0 & 73,6 & 76,2 \\
\hline Всего по Якутии & 64,0 & 66,6 & 60,6 & 65,4 & 68,9 & 70,1 & 71,1 \\
\hline
\end{tabular}

Обратимся к результатам социологического исследования «Качество жизни детей в Республике Саха», проведенного нами в 2016 г. в рамках реализации научного проекта «Этносоциальное развитие народов Республики Саха (Якутия) в условиях современного промышленного освоения и изменения социоприродной среды» (2013-2016 гг.) методом анкетного опроса родителей $(\mathrm{n}=383)$ (точки опроса: города Якутск, Мирный, Покровск ( $\mathrm{n}=235)$; села Верхневилюйск и Оргет Верхневилюйского улуса, село Магарас Горного улуса, село Немюгю Хангаласского улуса $(n=148))$. Анализ показал, что количеством дошкольных учреждений больше удовлетворены (по сумме ответов «полностью удовлетворены» и «скорее удовлетворены, чем не удовлетворены») респонденты из сельской местности, чем из городской, $-50,7$ против 36,2 \% соответственно. Наоборот, участники опроса из города считают недостаточным количество ДОУ в их месте проживания (по сумме ответов «скорее не удовлетворен(а), чем удовлетворен(а)» и «полностью не удовлетворен(а)») в отличие от сельчан - 49,8 против $31,1 \%$. Остальные затруднились ответить.

Большинство респондентов как из города, так и из села в целом положительно оценивают качество образования и воспитания в дошкольном учреждении. Распределение ответов находится в положительных границах, и все же отметим, что опрошенных из городов, давших оценки «отличное» и «хорошее», чуть больше, чем участников из сел, - 58,3 и 56,1 \% соответственно. Недовольны качеством образования в ДОУ больше родители из сел, чем из городов, отрицательные оценки («очень плохое» и «плохое») поставили 8,8 против 3,4 \%. 14,0 \% жителей городов и 14,2 \% сельчан не считают образование «ни хорошим, ни плохим». Для остальных данный вопрос оказался затруднительным.

Таким образом, отмечаемое на протяжении ряда лет сокращение количества дошкольных образовательных учреждений на фоне относительно благополучной демографической ситуации стало ограничивающим фактором для всестороннего и полноценного развития детей, возможностей социализации, что ущемляет право на общедоступность дошкольного образования и характеризуется как негативная ситуация. Однако развитие вариативности форм ДОУ позволяет увеличить количество мест для ведения образовательной деятельности по программам дошкольного образования, осуществления присмотра и ухода за детьми. Это в некоторой степени выравнивает положение в области получения услуг дошкольного образования (его доступности), что является позитивным аспектом изменений в рассматриваемой сфере. При этом возникает вопрос, касающийся различий в условиях и качестве предоставляемых услуг. В связи с этим актуально дальнейшее глубокое изучение выявленных проблем. Можно выделить следующие факторы, отрицательно влияющие на процесс социализации детей: наблюдаемое в динамике лет уменьшение числа дошкольных учреждений, неравномерность охвата детей по территориальному признаку, разное качество образования. 


\section{Ссылки и примечания:}

1. Антонова О.В. Роль детских дошкольных учреждений в социализации детей в условиях трансформации общества : автореф. дис. ... канд. социол. наук. Уфра, 2006. 27 с.

2. Жизненный мир россиян: 25 лет спустя (конец 1980-х - середина 2010-х гг.) / под ред. Ж.Т. Тощенко. М., 2016. 367 с.

3. Бюлер-Нидербергер Д., Зюнкер Х. От исследований социализации к социологии детства // Развитие личности. 2003. № 4. С. 69-94 ; Винокурова У.А. Воспитание и образование детей народов Севера. Якутск, 1997. 102 с. ; Гуркина О.А., Колосова Е.А. К вопросу об актуальности изучения детства в социологии // Вестник РГГУ. Сер.: Философия. Социология. Искусствоведение. 2013. № 2. С. 149-157 ; Демографические процессы в Республике Саха (Якутия): территориальный аспект / С.А. Сукнёва, Т.С. Мостахова, А.С. Барашкова и др. Якутск, 2017. 205 с. ; Детство XXI века в социогуманитарной перспективе: новые теории, явления и понятия : коллективная монография / науч. ред. С.Н. Майорова-Щеглова. М., 2017. 203 с. ; Детство XXI века: социогуманитарный тезаурус [Электронный ресурс] : тематический словарь-справочник / отв. ред. С.Н. Майорова-Щеглова. М., 2018. 638 с. 1 CD ROM ; Дюркгейм Э. Социология образования / под ред. В.С. Собкина, В.Я. Нечаева. М., 1996. 80 с. ; Игнатьева В.Б. Национальный состав населения Якутии: этностатистическое исследование. Якутск, 1994. 144 с. ; Кон И.С. Ребенок и общество. М., 1988. 269 с. ; Его же. Детство как социальный феномен // Журнал исследований социальной политики. 2004. Т. 2, № 2. С. 151-174 ; Нечаев В.Я. Новые подходы в социологии образования // Социологические исследования. 1999. № 11. С. 84-91; Парсонс Т. Аналитический подход к теории социальной стратификации // Социальная стратификация. М., 2000. С. 154-165 ; Сорокин П.А. Человек. Цивилизация. Общество. М., 1992. 543 с. ; Социология дошкольного детства. Труды по социологии образования. T. XVII, вып. XXIX / В.С. Собкин, К.Н. Скобельцина, А.И. Иванова, Е.С. Верясова. М., 2013. 167 с. ; Сукнёва С.А. Демографический потенциал развития населения северного региона. Новосибирск, 2010. 168 с. ; Фельдштейн Д.И. Психология взросления: структурно-содержательные характеристики процесса развития личности. М., 1999. 670 с.

4. Рассчитано по: Возрастно-половой состав населения Республики Саха Якутия на 1 января 2018 г. : статистический сборник № 24/537. Т. 2. Якутск, 2018. С. 96, 98 ; Социальное положение и уровень жизни населения Республики Саха (Якутия) : статистический сборник. Якутск, 2018. С. 36.

5. Социальное положение ... С. 44

6. Там же. С. 249

7. Там же. С. 250

8. Там же. С. 272

9. Итоговый отчет Министерства образования Республики Саха (Якутия) о результатах анализа состояния и перспектив развития системы образования за 2016 г. [Электронный ресурс] // Министерство образования и науки Республики Саха (Якутия) : официальный сайт. URL: https://minobrnauki.sakha.gov.ru/Ob-ispolnitelynom-OGV-RS--/Otcheti-vPravitelystvo-RS--/publichnye-doklady-mo-rsja (дата обращения: 01.07.2019).

10. Социальное положение .... С. 249-250.

\section{References:}

Antonova, OV 2006, The Role of Preschool Institutions in the Socialization of Children in the Context of Society Transformation, $\mathrm{PhD}$ thesis abstract, Ufa, 27 p., (in Russian).

Buehler-Niederberger, D \& Suenker, H 2003, 'From Studies on Socialization to the Sociology of Childhood', Razvitie lichnosti, no. 4, pp. 69-94, (in Russian).

Durkheim, E, Sobkin, VS \& Nechaev, VYa (eds) 1996, Sociology of Education, Moscow, 80 p., (in Russian).

Feldstein, DI 1999, Psychology of Growing Up: the Structural and Substantive Characteristics of the Personality Development Process, Moscow, 670 p., (in Russian).

Gurkina, OA \& Kolosova, EA 2013, 'Concerning the Relevance of the Study of Childhood in Sociology', Vestnik RGGU. Ser.:

Filosofiya. Sotsiologiya. Iskusstvovedenie, no. 2, pp. 149-157, (in Russian). Ignatyeva, VB 1994, Ethnic Composition of the Population of Yakutia: an Ethnic Statistical Study, Yakutsk, 144 p., (in Russian). Kon, IS 1988, Child and Society, Moscow, 269 p., (in Russian).

Kon, IS 2004, 'Childhood as a Social Phenomenon', Zhurnal issledovaniy sotsial'noy politiki, vol. 2, no. 2, pp. 151-174, (in Russian). Mayorova-Shcheglova, SN (ed.) 2017, Childhood of the 21st Century from the Social and Humanities Perspective: New Theories, Phenomena, and Concepts: a Multi-Authored Monograph, Moscow, 203 p., (in Russian).

Mayorova-Shcheglova, SN (ed.) 2018, Childhood of the 21st Century: Social and Humanities Tesaurus: a Theme-based Reference Book, Moscow, 638 p., (in Russian).

Nechaev, VYa 1999, 'New Approaches in the Sociology of Education', Sotsiologicheskie issledovaniya, no. 11, pp. 84-91, (in Russian).

Parsons, T 2000, 'An Analytical Approach to the Theory of Social Stratification', Sotsial'naya stratifikatsiya, Moscow, pp. 154-165, (in Russian).

Sobkin, VS, Skobeltsina, KN, Ivanova, Al \& Veryasova, ES 2013, Sociology of Preschool Childhood. Works on the Sociology of Education, vol. XVII, iss. XXIX, Moscow, 167 p., (in Russian).

Social Status and Living Standards of the Population of the Republic of Sakha (Yakutia): a Statistical Compilation 2018, Yakutsk, p. 36, 44, 249, 250, 272, (in Russian).

Sorokin, PA 1992, Person. Civilization. Society, Moscow, 543 p., (in Russian).

Suknyova, SA 2010, Demographic Development Potential of the Population in the Northern Region, Novosibirsk, 168 p., (in Russian). Suknyova, SA, Mostakhova, TS \& Barashkova, AS (et al.) 2017, Demographic Processes in the Republic of Sakha (Yakutia): a Territorial Aspect, Yakutsk, 205 p., (in Russian).

The Age and Sex Composition of the Population of the Republic of Sakha (Yakutia) as of January 01, 2018: a Statistical Compilation No. 24/537 2018, vol. 2, Yakutsk, pp. 96, 98, (in Russian).

'The Final Report of the Ministry of Education of the Republic of Sakha (Yakutia) on the Results of the Analysis of the State and Development Prospects of the Education System for 2016' 2019, Offical Website of the Ministry of Education and Science of the Republic of Sakha (Yakutia), viewed 01 July 2019, <https://minobrnauki.sakha.gov.ru/Ob-ispolnitelynom-OGV-RS--/Otchetiv-Pravitelystvo-RS--/publichnye-doklady-mo-rsja>, (in Russian).

Toshchenko, ZhT (ed.) 2016, Lifeworld of the Russians: 25 Years Later (the Late 1980s - Mid-2010s): a Scientific Publication, Moscow, 367 p., (in Russian).

Vinokurova, UA 1997, Education and Upbringing of the Indigenous Children of the North, Yakutsk, 102 p., (in Russian). 